\title{
UV variability in Moscow according to long-term UV measurements and reconstruction model
}

\author{
N. Y. Chubarova \\ Faculty of Geography, Moscow State University, Moscow, Russia \\ Received: 5 December 2007 - Published in Atmos. Chem. Phys. Discuss.: 18 January 2008 \\ Revised: 19 May 2008 - Accepted: 19 May 2008 - Published: 18 June 2008
}

\begin{abstract}
Long-term measurements of erythemally weighted UV irradiance $\left(\mathrm{Q}_{e r}\right)$ have been analyzed for the 1999-2006 period as well as UV variability according to a reconstruction model since 1968. The estimates of different atmospheric parameters effects, including $\mathrm{NO}_{2}$ content, on $\mathrm{Q}_{e r}$ have been obtained on seasonal and interannual scales. It has been shown that $\mathrm{NO}_{2}$ content in conditions of large megalopolis provides average $\mathrm{Q}_{e r}$ decrease of about $1.5-2 \%$. The seasonal variations of the observed UV indices are discussed from the point of view of the impact on health. Using the reconstruction model we showed a distinct growth in $\mathrm{Q}_{e r}$ since 1980 due to changes in total ozone $(+2.5 \%$ per decade), effective cloud amount transmission $(+2.1 \%$ per decade) and aerosol loading ( $+1.1 \%$ per decade). However, there is no change in $\mathrm{Q}_{e r}$ over the longer 1968-2006 period due to significant decrease in effective cloud amount transmission $(-11 \%$ per decade) in $1968-1980$.
\end{abstract}

\section{Introduction}

Ultraviolet (UV) irradiance has a strong influence on the biosphere (UNEP, 1994). During last decades significant efforts were made for organizing UV monitoring from space and at the ground by different devices in order to assess the temporal and spatial variability of UV irradiance over the world (WMO, 2007). In this paper we analyse the main features of erythemally-weighted $\left(\mathrm{Q}_{e r}\right)$ irradiance in Moscow on the base of long-term ground measurements using broadband UV-B instrument and supplementary meteorological information including cloud and aerosol properties, surface albedo, and trace gas species content. In order to understand the cause of $\mathrm{Q}_{e r}$ variations we have analyzed the specific fea-

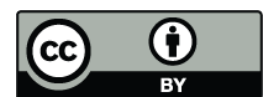

Correspondence to: N. Y. Chubarova (chubarova@imp.kiae.ru) tures of typical seasonal variation of main parameters and have made the estimates of their impact on $\mathrm{Q}_{e r}$. Moscow is a big city with high traffic and many power stations, which can provide high emissions of $\mathrm{NO}_{\mathrm{x}}$ and, accordingly, high $\mathrm{NO}_{2}$ content. Hence, special attention should be paid to estimating $\mathrm{NO}_{2}$ effects on $\mathrm{Q}_{e r}$ during different seasons.

The level of UV indices in diurnal and seasonal cycles is characterized from the point of view of the impact on health. For this purpose two simple thresholds have been applied: one threshold - for protection from erythema according to (Vanicek et al., 2000) and the second threshold - for the vitamin D synthesis from (Holick and Jenkins, 2003). This approach allows to characterize Moscow conditions from the point of view of human health and to obtain time periods with unfavourable UV conditions.

Because of large interannual variations of the atmospheric parameters $\mathrm{Q}_{e r}$ can undergo significant changes in the past. And, as many biological and health related effects depend on UV dose accumulated during long period, the assessment of possible UV irradiance changes in the previous decades is very important. To evaluate the UV-B irradiance in the past different sorts of reconstruction models have been applied, which use various kinds of statistical or model approaches and different meteorological or radiation datasets (Kaurola et al., 2000; Fioletov et al., 2001; Krzyscin et al., 2004; den Outer et al., 2005; Chubarova et al., 2005; Lindfors and Vuilleumier, 2005; Lindfors et al., 2007, etc). We have used the approach described in Chubarova et al. (2005) to reconstruct $\mathrm{Q}_{e r}$ variability, to estimate the role of different atmospheric factors, and also to compare reconstructed interannual $\mathrm{Q}_{e r}$ variations with the measured ones.

\section{Method and data description}

The UV-B monitoring in Moscow has been in operation by broadband UVB-1 YES pyranometers at the Meteorological 
Observatory of Moscow State University (MO MSU) since 1999. Initially all the instruments were tested at NREL laboratory of Colorado State University (courtesy of D. Bigelow and J. Slusser) in 1998 and directly at YES. Inc. company. Then they were cross-calibrated against the reference instrument, which in turn was calibrated in erythemallyweighted units against the ultraviolet spectroradiometer Bentham DTM-300 of the Medical University of Innsbruck in 1999 (Bais et al., 1999) and directly in Innsbruck in 2005 (courtesy of M. Blumthaler). The corrections on total ozone and solar zenith angle have been applied to the initial data in order to minimize the errors for high solar zenith angles and large ozone content according to (Lantz et al., 1999; Chubarova, 2002). They are also in accordance with recommendations described in (Seckmeyer et al., 2006).

The UV reconstruction model used in this study is described in details in (Chubarova and Nezval, 2000; Chubarova et al., 2005). However, for better understanding of the results, the main characteristics of the model are shown below. The model is based on the assumption that the year-to-year UV variability $V_{i}$ can be written as a sum of $\mathrm{UV}$ variations due to variations in total ozone $v 1$, aerosol optical thickness $v 2$, cloud optical thickness $v 3$, and cloud amount $v 4$ with account of surface albedo $A$ and monthly weights $W_{j}$ of solar angle $h$ :

$$
\begin{aligned}
V_{i}= & \sum_{j}\left(W _ { j } ( h ) \left(v 1_{i, j}(X)+v 2_{i, j}\left(\tau_{a}, P_{c f}, A\right)\right.\right. \\
& \left.+v 3_{i, j}\left(\tau_{c}, P_{o v}\right)+v 4_{i, j}\left(C Q_{A}\right)\right) / \sum_{j} W_{j}(h)
\end{aligned}
$$

where index $i$ corresponds to a year number, index $j$ - to a month number; $X$ is the total ozone content; $\tau_{a}$ and $\tau_{c}$ are an aerosol and cloud optical thickness; $P_{c f}$ and $P_{o v}$ are the occurrences of clear sky and overcast cloud conditions. UV variability due to cloud amount $(v 4)$ was estimated using the effective cloud amount transmission $\left(C Q_{A}\right)$. The influence of surface albedo on this characteristic is accounted in the form of geometric progression:

$C Q_{A}=\frac{C Q_{A=0}}{1-A\left(C-D C Q_{A=0}\right)}$

where $C \sim 0.9$ and $D \sim 0.6$ according to the model simulations.

The $C Q_{A=0}$ is determined as a combination of relative frequency of different cloud amounts weighted on their UV transmission:

$$
\begin{aligned}
C Q_{A=0}= & \sum_{N L=0}^{10}\left\{[P(N l)-P(N l, N=10)] \cdot C Q_{A=0}(N l)\right. \\
& \left.+P(N l, N=10) \cdot C Q_{A=0}(N l) \cdot C Q_{u p}\right\}
\end{aligned}
$$

Here, $P(N l)$ is the frequency of low layer cloud amount $(N l)$ with different amounts of total cloudiness for a given month, $P(N l, N=10)$ - is the frequency when total cloud amount is equal to $N=10$, always corresponding to overcast conditions but with different amount of low layer clouds; $C Q_{, A=0}(N l)$ - is the UV transmission by low layer cloudiness; $C Q_{u p}=0.93$ is a mean UV transmission by overcast upper layer cloudiness. The second term of Eq. (3) accounts for the UV transmission in overcast cloud conditions, while all other situations are considered in the first term. This equation is obtained with the assumption that upper level clouds do not affect the UV transmission except when overcast with upper level clouds. Therefore this method independently accounts for UV transmission by optically thick low-level cloudiness and thin upper level clouds.

The UV transmission of different cloud amount has been evaluated on the base of long-term measurements of UV irradiance of 300-380 nm (Chubarova, 1998). UV transmission is known to have some spectral features in its attenuation (see, for example, Chubarova et al., 1996, Lindfors and Kylling, 2008). However, our model calculations have shown quite similar effects of clouds on UV irradiance 300$380 \mathrm{~nm}$ and $\mathrm{Q}_{e r}$ due to minor difference in their effective wavelengths with few percents higher $\mathrm{Q}_{e r}$ cloud transmission. Whereas we are interested in relative changes of UV irradiance, we neglect this small difference.

The surface albedo $A$ was estimated using the following equation:

$A=w_{A} A_{1}+\left(1-w_{A}\right) A_{2}$

where $A_{1}=0.4$ is the albedo of snow, $A_{2}=0.02$ is the grass albedo. The value of snow albedo is in accordance with the typical TOMS MLER values over Moscow (Chubarova et al., 2002). The $w_{A}$ is a weighting coefficient, which accounts for snow occurrence, estimated using a standard meteorological characteristic - spatial snow coverage.

The model of reconstruction does not include the effects of changes in the vertical profiles of temperature and ozone which were shown to have the effects on UV-B irradiance (McKenzie et al., 2003). This factor has been neglected due to lack of information on ozone vertical profiles in the past.

This reconstruction model has been successfully verified against 1968-1997 dataset of UV irradiance 300-380 nm (Chubarova and Nezval, 2000), satellite TOMS and METEOSAT retrievals (Chubarova et al., 2005) and some other data. In addition, the reconstruction model has been carefully tested against exact model calculations based on 8 stream DISORT method incorporated in the TUV model (Madronich and Flocke, 1998). For the large range of atmospheric parameters (total ozone of 250-450 DU, aerosol optical thickness at $380 \mathrm{~nm}$ (AOT380) of 0.05-0.6, cloud optical thickness of 0-60) this approach was shown to have an uncertainty of less than $2 \%$ compared with the accurate model calculations. The uncertainty is larger in situations with high loading of absorbing aerosol with single scattering albedo (SSA) less than 0.85 , which are rarely observed.

In order to characterise the atmospheric parameters, various datasets were applied. Two aerosol datasets are used in the study: the Moscow AERONET dataset at level 2, version 
2 with additional cloud filtering according to (Ulyumdzhieva et al., 2005) which provides AOT340 and Angstrom parameter, and 1968-2006 AOT550 dataset. The AOT550 is calculated using direct shortwave irradiance and water vapour content according to the method described in (Tarasova and Yarkho, 1991). The estimated AOT550 values were carefully tested against AERONET AOT measurements. The test has confirmed the absence of the bias for AOT550 less 0.5 but only if AOT550 is calculated with Angstrom parameter of $\alpha=1$ instead of the observed $\alpha=1.4$. Typical SSA in UV spectral region is about 0.92 , which was calculated using Mie theory with the optical parameters taken from AERONET dataset in visible spectral region. The dataset of cloud optical thickness for 1968-2006 period was obtained according to the method developed by Tarasova and Chubarova (1994) with the use of global shortwave irradiance measurements in overcast cloud conditions in Moscow.

The preliminary analysis of the influence of different small gas species on $\mathrm{Q}_{e r}$ in Moscow conditions has revealed the most pronounced effects of $\mathrm{NO}_{2}$ (Chubarova, 2006). To estimate total $\mathrm{NO}_{2}$ content a combination of surface $\mathrm{NO}_{2}$ measurements from TE42C-T gas analyzer and model vertical profile in the low $2 \mathrm{~km}$ has been applied following the methology described in (Chubarova and Dubovik, 2004).

In addition, we used the long-term measurements of UV 300-380 nm irradiance (Q380) (Chubarova and Nezval, 2000) to compare interannual Q380 changes, which are not practically influenced by the ozone, with the changes in erythemally-weighted irradiance.

\section{Seasonal changes of main atmospheric parameters and their effects on UV irradiance}

In order to explain the main features of UV seasonal variability it is necessary to analyze variations of main parameters affecting UV. Figure 1 presents mean seasonal changes in total ozone content, aerosol and $\mathrm{NO}_{2}$ optical thickness, effective cloud amount transmission with account for spatial snow albedo $\left(\mathrm{CQ}_{A}\right)$ and without it $\left(\mathrm{CQ}_{A=0}\right)$ for 1999-2006 period, and seasonal dependence of the sine of noon solar angles in Moscow. Solar angle is, of course, a dominating factor in UV irradiance change, however, we can see some interesting features in seasonal variations of other parameters. In ozone variations we observe typical for high latitudes a strong seasonal cycle with the maximum in spring (March) and the minimum in the fall similar to the $\mathrm{CQ}_{A}$ variations which, in addition, have large values during summer time. The $\mathrm{CQ}_{A}$ values have the maximum in March due to less cloud amount and still presence of snow on the surface. According to our estimates (see the Eq. 2) snow can increase the $\mathrm{CQ}_{A=0}$ values on about $0.15-0.17$ during winter months. AOT340 also has the maximum in spring, in April, due to the absence of vegetation at ground and low precipitation, that lead to the increase of dust particles in the air. The second
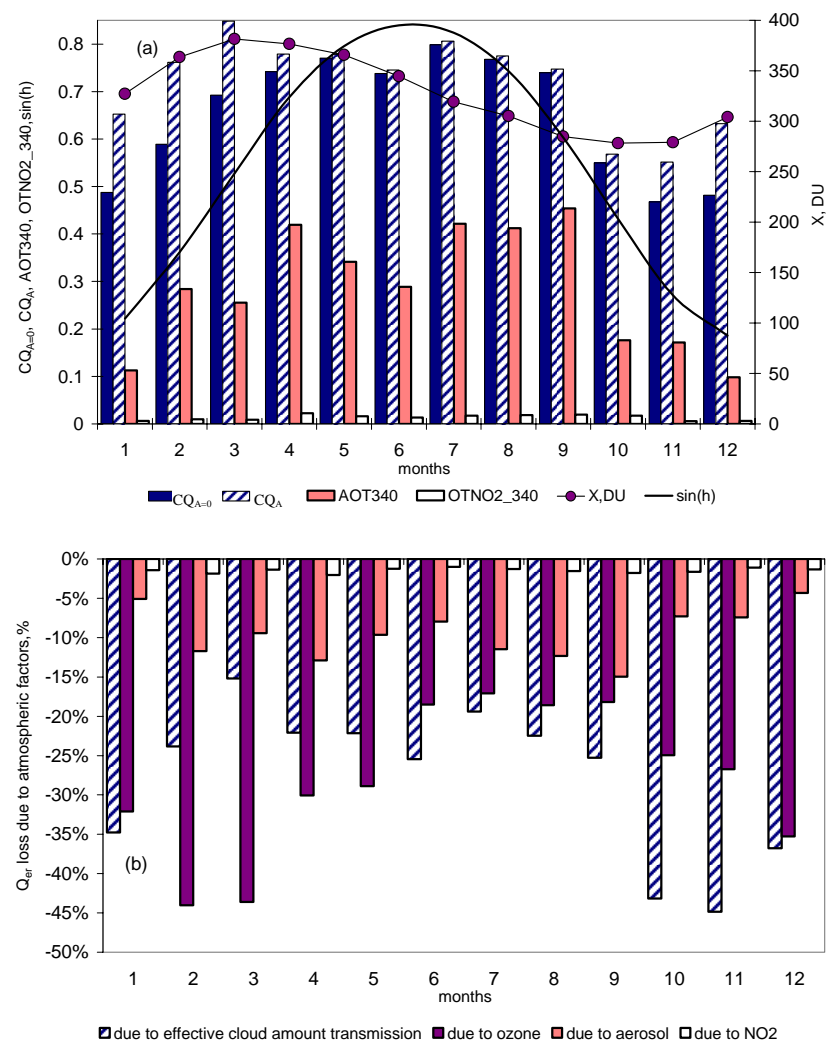

Fig. 1. (a) Average seasonal changes in total ozone (X), aerosol optical thickness at $340 \mathrm{~nm}$ (AOT340), $\mathrm{NO}_{2}$ optical thickness at $340 \mathrm{~nm}\left(\mathrm{OTNO}_{2} 340\right)$, effective cloud amount transmission $\left(\mathrm{CQ}_{A}\right.$ and CQ) as well as the sine of noon solar angle (sinh). (b) Relevant seasonal $\mathrm{Q}_{\text {er }}$ loss due to monthly mean effective cloud amount transmission, aerosol, ozone, and $\mathrm{NO}_{2}$ factors. 1999-2006. The loss is calculated as a relative difference in $\mathrm{Q}_{e r}$ calculated with account and with no account for the analyzed factor. In case of ozone, the daily minima from 1979-2003 TOMS data series were taken as a proxy for theoretically lowest monthly ozone values over Moscow.

summer-fall maximum is explained by many factors: predominant air mass advection from the south, lack of precipitation and the effects of forest fires. There are also spring and summer maxima in the $\mathrm{NO}_{2}$ content; the mean $\mathrm{OT}_{\mathrm{NO} 2}$ at $340 \mathrm{~nm}$ is rather small $(0.01-0.02)$ but still pronounced.

Figure $1 \mathrm{~b}$ presents seasonal variation of mean $\mathrm{Q}_{e r}$ losses due to different atmospheric parameters, which have been estimated using TUV model, except effective cloud amount transmission, calculated using the Eqs. (2) and (3). It is clearly seen that cloudiness is a dominating factor in summer and in the fall while during February-May period total ozone plays more important role in $\mathrm{Q}_{e r}$ attenuation. The $\mathrm{Q}_{e r}$ mean loss due to AOT varies from $4 \%$ in winter to $12-15 \%$ in April and July-September periods. The $\mathrm{Q}_{e r}$ loss due to $\mathrm{NO}_{2}$ is about $1.5-2 \%$ throughout the year, except May-June. The higher $\mathrm{Q}_{e r}$ sensitivity to $\mathrm{NO}_{2}$ in winter is explained by the bias of the $\mathrm{Q}_{e r}$ effective wavelength at smaller solar elevation 

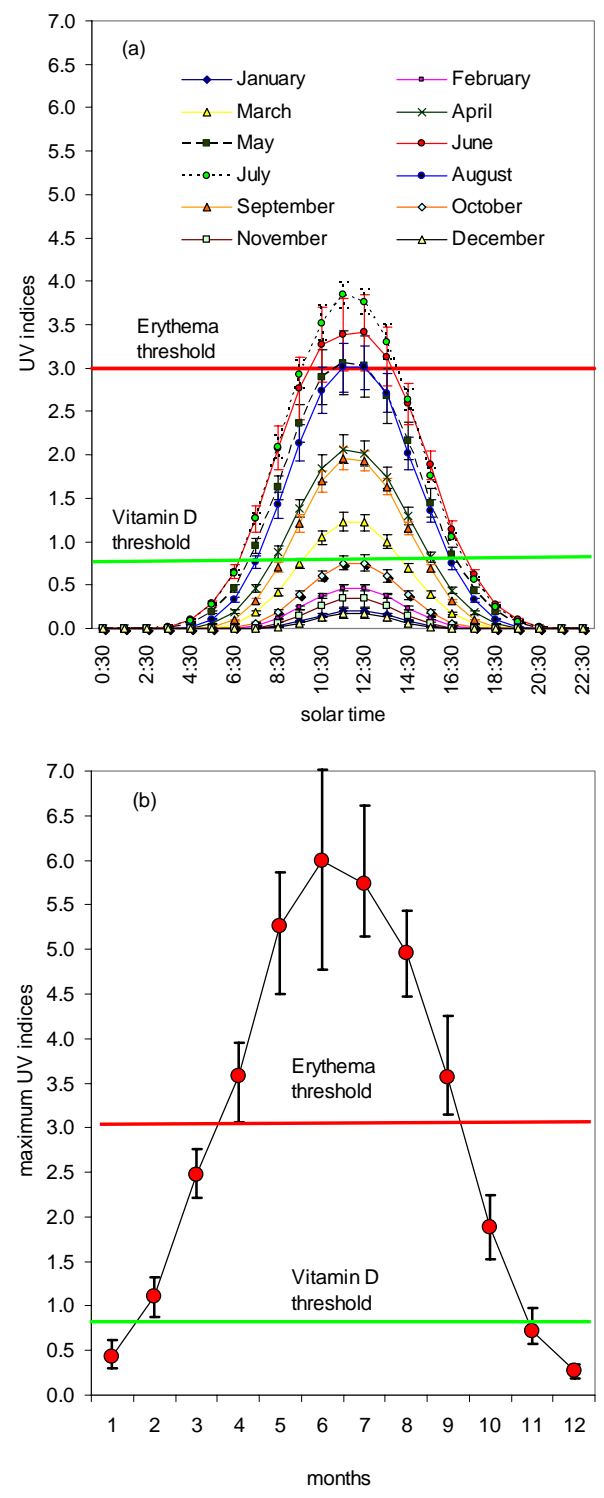

Fig. 2. (a) Diurnal cycle of average UV indices in Moscow with the confidence intervals at $95 \%$ for interannual changes. (b) Seasonal changes in mean UVI maxima for each month. Here error bars show the range in UVI maxima observed during 1999-2006 period. Threshold for erythema is according to (Vanicek et al., 2000); threshold for vitamin D synthesis - according to (Holick, Jenkins, 2003) for skin type 2. 1999-2006 period.

to longwave spectral region where there is higher $\mathrm{NO}_{2}$ absorption.

It was interesting to make assessments of the $\mathrm{Q}_{e r}$ response to the heterogeneity of aerosol loading within the city. For this purpose a special experiment has been organized with simultaneous measurements by AERONET CIMEL sun photometer at MO MSU and cross-calibrated GLOBE portable sun photometer in different parts of the Moscow area during summer of 2005 (case number is about 80). The fre- quency distribution of the obtained AOT500 differences lies in accordance with normal law and has zero bias. The difference reaches \pm 0.06 at $95 \%$ significance level that according to model calculations leads to $\pm 3-4 \%$ additional variations in $\mathrm{Q}_{e r}$, due to heterogeneity of aerosol distribution over Moscow.

Figure 2a shows average diurnal cycle of hourly UV indices (UVI) in different months over 1999-2006 period. Noon UVI values in summer can be 24 times larger than those observed in winter. Special attention has been paid to the determination of time periods with unfavourable UV conditions for human health. According to Vanicek et al. (2000) the UV protection is required when UVI are higher than 3 . In Moscow for mean (typical) conditions UVI are higher than 3 (but less than 4) only at 10:30-13:30 in June and July and at 11:30-12:30 in May and August. Similar noon UV indices in August and May can be explained by compensating for UV decrease due to higher aerosol loading and slightly lower solar angles observed in August with the UV increase due to seasonal lower ozone amount (see Fig. 1). At the same time, the maximal observed UV indices can reach middle (UVI=46) and even high (UVI=6-7) categories through April to September (see Fig. 2b). The maximum hourly UVI value (UVI=7) observed in Moscow was recorded at noon time 27 June 2004, when total and low layer cloud amount were equal to 6 providing additional scattering from the cloud sides, sun disk was unobscured by cloud, total ozone $\mathrm{X}$ of 303 DU and AOT340 of 0.25 were reduced against climatic values (see Fig. 1a).

According to the recommendations described in (Holick, Jenkins, 2003), the time, which is necessary for vitamin D synthesis, is based on a threshold of $25 \%$ of Minimal Erythemal Dose. Using this simple approximate threshold we show the inability to get vitamin D for any skin type in typical meteorological conditions even at noon from October (except skin type 1) to February. Furthermore, even in conditions favourable for creating high UV level it is impossible to get vitamin D in December for any of skin types and in January (for any, except skin type 1). In November and February only at the highest UV levels it is possible to get vitamin D for skin types 1 and 2, which are most sensitive to UV impact.

\section{The long-term UV variations}

Figures $3 \mathrm{a}, \mathrm{b}$ presents $\mathrm{Q}_{e r}$ variations due to different atmospheric parameters for 1968-2006 period as well as reconstructed and observed long-term $\mathrm{Q}_{e r}$ variability. In addition, Fig. 3c shows the interannual variations of measured and reconstructed UV irradiance 300-380 nm (Q380), which has negligible dependence on ozone. There is quite satisfactory agreement between measured and model values that has confirmed a good quality of the reconstruction model. Some difference between the observed and reconstructed UV irradiance can be also caused by the uncertainty of broadband 
UV measurements, which is about 5\%. Due to variations in atmospheric factors the $\mathrm{Q}_{e r}$ interannual changes are about $\pm 16 \%$ during warm period. The influence of $\mathrm{CQ}_{A}$ on $\mathrm{Q}_{e r}$ variability is dominant explaining about $10 \%$ of the variations while the ozone effects are slightly less $( \pm 8 \%)$. The predominant role of cloudiness is in accordance with our estimates shown in Fig. $1 \mathrm{~b}$ for the warm period. Interannual changes in aerosol loading also play a noticeable role, providing $\mathrm{Q}_{e r}$ variation of $\pm 2-3 \%$ while the role of cloud optical thickness is quite small $( \pm 1.5 \%)$ in Moscow.

In addition to high frequency and/or random $\mathrm{Q}_{e r}$ variations, one can see pronounced low frequency variability in $\mathrm{Q}_{e r}$ response to ozone, cloudiness and aerosol optical thickness changes and in $\mathrm{Q}_{e r}$ itself (see Figs. 3a,b). On the whole, since 1980 we can reveal linear statistically significant positive trends in $\mathrm{Q}_{e r}$ due to decrease in ozone of about $+2.5 \%$ and due to aerosol variations of about $+1.1 \%$ per decade. The reduction of aerosol loading has global character: it is observed at least for the whole Russian territory (Makhotkina et al., 2005). The substantial growth of effective cloud amount transmission at the end of the century has not continued during the last few years since 2003 but still there is statistically significant increase in $\mathrm{Q}_{e}$ due to $\mathrm{CQ}_{A}$ of about $+2.1 \%$ per decade since 1980 . Hence, all atmospheric factors result in $\mathrm{Q}_{e r}$ increase, which is estimated to $+6 \%$ per decade since 1980. This means that at present time $\mathrm{Q}_{e r}$ is about 15$20 \%$ higher than at the beginning of the 1980s. At the same time during 1968-1980 period the significant drop in $\mathrm{Q}_{e r}$ of $-13.8 \%$ is explained by strong $\mathrm{CQ}_{A}$ decrease of $-11 \%$ per decade. On the average, for the whole 1968-2006 period no statistically significant trend in $\mathrm{Q}_{e r}$ has been revealed. These results are in agreement with the $\mathrm{Q}_{e r}$ reconstructions over Central and Eastern Europe shown in (Krzyscin et al., 2004), where a pronounced drop in $\mathrm{Q}_{e r}$ in the late 1970s as well as $\mathrm{Q}_{e r}$ increase in the 1990s has been obtained.

Figure $3 \mathrm{c}$ shows the similar character of UV irradiance 300-380 nm interannual changes but with less pronounced variations (within $\pm 10 \%$ ) than those obtained for $\mathrm{Q}_{e r}$. There is also the absence of further Q380 increase since 2003 due to a tendency of reduction in effective cloud amount transmission from its level on the frontier of the centuries (see the blue curve in Fig. 3a). At the same time, the Q380 level during the last years is still about $10 \%$ higher than it was observed at the beginning of 1980s. However, this growth is significantly less than that estimated for $\mathrm{Q}_{e r}$ due to the additional influence of ozone decrease on erythemally-weighted irradiance during the last years.

\section{Conclusions}

Measurements and reconstruction of erythemally weighted irradiance have revealed its significant seasonal and interannual variations due to different atmospheric parameters. The role of effective cloud amount transmission and total ozone
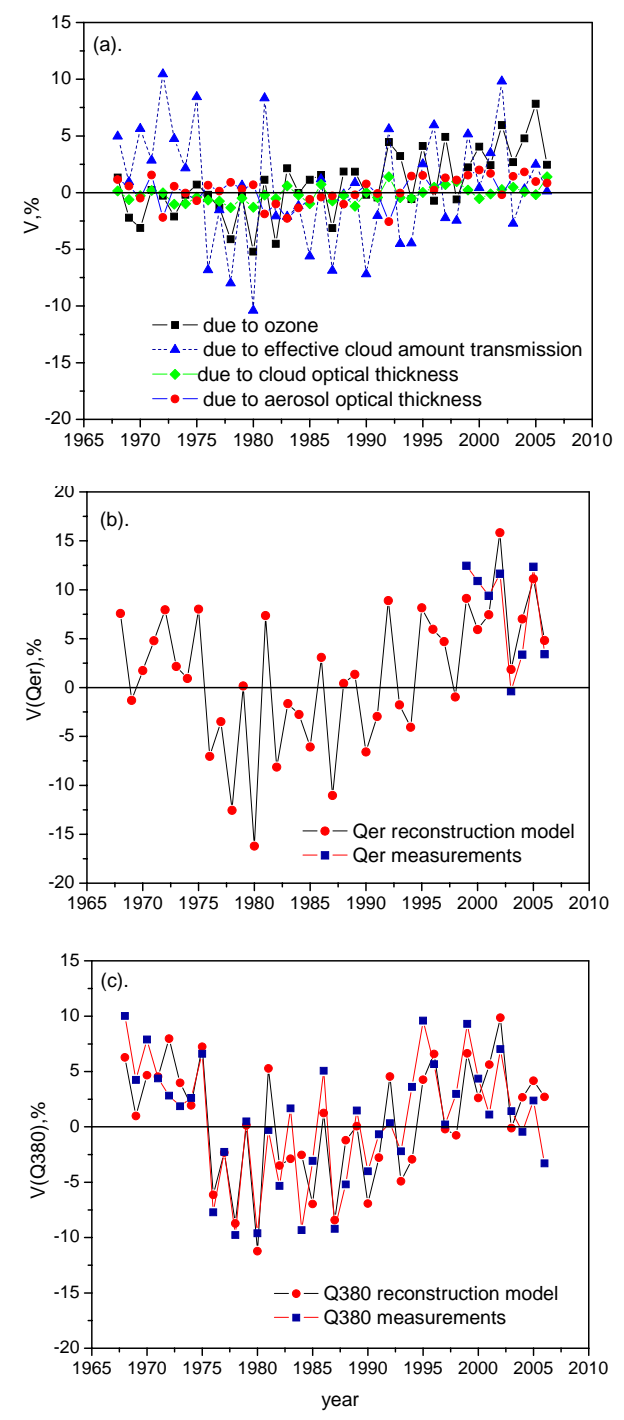

Fig. 3. (a) Changes in $\mathrm{Q}_{e r}$ due to variations in total ozone, effective cloud amount transmission, aerosol and cloud optical thickness according to the reconstruction model. (b) Observed and reconstructed interannual $\mathrm{Q}_{e r}$ variability. (c) Observed and reconstructed interannual Q380 variability. All the data are normalized on 19681997 period. May-September, Moscow.

in $\mathrm{Q}_{e r}$ perturbation was confirmed as most significant (15$45 \%$ ) but their role was shown to change in seasonal cycle with maximum effects due to ozone in spring and due to cloudiness - in summer and in the fall. The change in aerosol loading can attenuate $\mathrm{Q}_{e r}$ by 4-15\% with minimum in winter and maximum in April and July-September. The mean effects of $\mathrm{NO}_{2}$ on the $\mathrm{Q}_{e r}$ attenuation are small but still detectable (1.5-2\%).

The analysis of seasonal changes of UV indices has shown that mean noon UVI are 24 times higher in summer than in winter. Using the erythema threshold we have revealed that in typical conditions the $\mathrm{UV}$ radiation protection is necessary 
at 10:30-13:30 in June and July and at 11:30-12:30 in May and August. However, maximal UV indices can reach middle and high categories through April to September. Using the approximate threshold for vitamin D synthesis from (Holick and Jenkins, 2003) we have shown the inability to get vitamin $\mathrm{D}$ for any of skin types in typical meteorological conditions even at noon from October (except skin type 1) to February. And in conditions favourable for the highest UV levels it is impossible to get vitamin D for any of skin types in December and January (except skin type 1). This provides quite unfavourable conditions for human health during long cold period in the Moscow area.

The reconstructed long-term changes in $\mathrm{Q}_{e r}$ irradiance show a good agreement with the measured values during 1999-2006. The $\mathrm{Q}_{e r}$ interannual changes comprises $\pm 16 \%$ due to the variations in effective cloud amount transmission $( \pm 10 \%)$, total ozone $( \pm 8 \%)$ and aerosol loading $( \pm 2-3 \%)$. The $\mathrm{Q}_{e r}$ growth of about 6\% per decade since 1980 is explained by its increase due to changes in ozone $(+2.5 \%$ per decade), effective cloud amount transmission $(+2.1 \%$ per decade) and aerosol loading ( $+1.1 \%$ per decade). At the same time, the analysis of the $\mathrm{Q}_{e r}$ over 1968-2006 period has revealed the absence of trend because of significant drop $(-11 \%$ per decade) in effective cloud amount transmission which took place during 1968-1980. There is the same tendency in interannual changes of $\mathrm{Q}_{e r}$ and Q380. At the same time, due to ozone effects there are much more pronounced variations in $\mathrm{Q}_{e r}$ and its more significant growth in the late 1990s. However, since 2003 the increase in both $\mathrm{Q}_{e r}$ and Q380 has not continued due to a tendency of reduction in effective cloud amount transmission from its level on the frontier of the centuries. The $\mathrm{Q}_{e r}$ variability over Moscow agrees well with the $\mathrm{Q}_{e r}$ reconstructed data series over Central and Eastern Europe (Krzyscin et al., 2004) with a pronounced drop in the late 1970s and the increase in the 1990s. This confirms the global character of the observed $\mathrm{Q}_{e r}$ variability.

Acknowledgements. This work was partly supported by the International Science \& Technology Center (project \# 3254).

Edited by: M. Blumthaler

\section{References}

Bais, A., Topaloglou, C., Kazadtzis, S., Blumthaller, M., Schreder, J., Schmalwieser, A., Henriques, D., and Janouch, M.: Report of the LAP/COST/WMO. Intercomparison of Erythemal Radiometers, (Thessaloniki, Greece, 13-23 September 1999), WMO TD, 1051, 54 pp., 1999.

Chubarova, N.Ye., Krotkov, N. A., Geogdzhayev, I. V., Kondranin, T. V., and Khatattov, V. U.: Spectral UV Irradiance: the Effects of Ozone, Cloudiness and Surface Albedo / IRS'96 Current problems in Atmospheric Radiation. A Deepak Publishing, Hampton, Virginia USA, 881-885, 1997.

Chubarova, N. and Nezval, Ye.: Thirty year variability of UV irradiance in Moscow, J. Geophys. Res. Atmos., 105, 12 529-12 539, 2000.

Chubarova, N.: Monitoring of Biologically Active UV Radiation in the Moscow Region, Izvestiya, Atmospheric and Oceanic Physics, 38, 3, 312-322, 2002.

Chubarova, N., Yurova, A., Krotkov, N., Herman, J., and Bhartia, P. K.: Comparisons between ground measurements of broadband UV irradiance (300-380 nm) and TOMS UV estimates at Moscow for 1979-2000, Opt. Eng., 41, 12, 3070-3081, 2002.

Chubarova, N. and Dubovik O.: The sensitivity of aerosol properties retrievals from AERONET measurements to NO2 concentration over industrial region on the example of Moscow, Optica Pura y Aplicada, 37, 3, 3315-3319, http://www.sedoptica. es/indice.html, 2004.

Chubarova, N., Nezval, Ye. I., Verdebout, J., Krotkov, N., and Herman, J.: Long-term UV irradiance changes over Moscow and comparisons with UV estimates from TOMS and METEOSAT, "Ultraviolet Ground- and Space-based Measurements, Models, and Effects" edited by: Bernhard, G., Slusser, J. R., Herman, J. R., and Gao, W., SPIE, 63-73, 2005.

Chubarova, N. E.: Role of tropospheric gases in the absorption of UV radiation, Dokl. Earth Sci., 407, 2, 294-297, 2006.

den Outer, P. N., Slaper, H., and Tax, R. B.: UV radiation in the Netherlands: Assessing long-term variability and trends in relation to ozone and clouds, J. Geophys. Res., 110, D02203, doi:10.1029/2004jd004824, 2005.

Fioletov, V. E., McArthur, L., Kerr, J. B., and Wardle, D. I.: Longterm variations of UV-B irradiance over Canada estimated from Brewer observations and derived from ozone and pyranometer measurements, J. Geophys. Res., 106, 23 009-23 028, 2001.

Holick, M. F. and Jenkins, M.: The UV advantage: new medical breakthroughs reveal powerful health benefits from sun exposure and tanning, A publication of ibooks, inc., 2003.

Kaurola, J., Taalas, P., Koskela, T., Borkowski, J., and Josefsson, W.: Long-term variations of UV-B doses at three stations in northern Europe, J. Geophys. Res., 105, 20 813-20 820, 2000.

Krzyscin, J. W., Eerme, K., and Janouch, M.: Long-term variations of the UV-B radiation over Central Europe as derived from the reconstructed UV time series, Ann. Geophys., 22, 1473-1485, 2004 , http://www.ann-geophys.net/22/1473/2004/.

Lantz, K. O., Disterhoft, P., DeLuisi, J. J., Early, E., Thompson, A., Bigelow, D., and Slusser, J.: Methodology for deriving clear-sky erythemal calibration factors for UV broadband radiometers of the US Central Calibration Facility, J. Atmos. Ocean. Tech., 1, 1736-1752, 1999.

Lindfors, A. and Vuilleumier, L.: Erythemal UV at Davos (Switzer- 
land), 1926-2003, estimated using total ozone, sunshine duration, and snow depth, J. Geophys. Res., 110 (D2), D02104, doi:10.1029/2004JD005231, 2005.

Lindfors, A., Kaurola, J., Arola, A., Koskela, T., Lakkala, K., Josefsson, W., Olseth, J. A., and Johnsen, B.: A method for reconstruction of past UV radiation based on radiative transfer modeling: Applied to four stations in northern Europe, J. Geophys. Res., 112, D23201, doi:10.1029/2007JD008454, 2007.

Lindfors, A. and Arola A.: On the wavelength-dependent attenuation of UV radiation by clouds, Geophys. Res. Lett., 35, L05806, doi:10.1029/2007GL032571, 2008.

Madronich, S. and Flocke, S.: The role of solar radiation in atmospheric chemistry, in: Handbook of Environmental Chemistry, edited by: Boule, P., Springer-Verlag, Heidelberg, 1-26, 1998.

Makhotkina, E. L., Plakhina I. N., and Lukin, A. B.: Some features of Atmospheric turbidity change over the Russian territory in the last quarter of the 20th century, Russian Meteorology and Hydrology (Meteorologiya i Gidrologiya), Allerton Press, No.1, 20-27, 2005.

McKenzie, R., Smale, D., Bodeker, G., and Claude, H.: Ozone profile differences between Europe and New Zealand: Effects on surface UV irradiance and its estimation from satellite sensors, J. Geophys. Res. 108, D6, 4179, doi:10.1029/2002JD002770., 2003.
Seckmeyer, G., Bais, A., Bernhard, G., Blumthaler, M., Booth, C. R., Lantz, K., and McKenzie, R. L.: Instruments to measure solar ultraviolet irradiance. Part 2: Broadband instruments measuring erythemally weighted solar irradiance, WMO, Global Atmospheric Watch No. WMO TD, No. 1289, 51 pp., 2006.

Tarasova, T. A. and Yarkho, E. V.: Determination of aerosol optical thickness using measurements of direct integral solar radiation, Soviet Meteorology and Hydrology, (English translation), 12, 66-71, 1991.

Tarasova, T. and Chubarova, N.: On the calculation of optical thickness of extended low and middle clouds using measurements of solar radiation in three solar spectrum ranges on the Earth's surface, Izvestiya Atmospheric and Oceanic Physics, (English translation), 30, 253-257, 1994.

Ulyumdzhieva, N., Chubarova N., and Smirnov A.: Aerosol characteristics of the atmosphere over Moscow from Cimel sun photometer data, Russian Meteorology and Hydrology, 1, 37-44, 2005.

Vanicek, K., Frei, T., Litynska Z., and Shmalwieser, A.: UV-Index for the Public, COST-713 Action, Brussels, 27 pp., 2000.

WMO: Scientific Assessment of Ozone Depletion: 2006, Global Ozone Research and Monitoring Project - Report No. 50, 572 pp., Geneva, Switzerland, 2007. 